\title{
ASSOCIATION BETWEEN KNOWLEDGE, ATTITUDE, AND PRACTICE ABOUT DIETARY FIBRE INTAKE AND TYPE 2 DIABETES AMONG RURAL PEOPLE IN TERENGGANU, MALAYSIA
}

\author{
San San Oo, Myat Moe Thwe Aung, Charan Kishor Shetty, Mohd Salami Ibrahim, Nyi Nyi Naing, Yuzana Binti \\ Mohd Yusop, Azmi Hassan, Intan Suhana Munira Mat Azmi and Safiya Amaran \\ ${ }^{1}$ Universiti Sultan Zainal Abidin, Kampus Perubatan, Jln Sultan Mahmud, 20400, Kuala Terengganu, Malaysia
}

Corresponding author: Nyi Nyi Naing

Email: syedhatim@unisza.edu.my

\begin{abstract}
Awareness of the dietary fibre intake (DF) and its importance in prevention and management of type 2 diabetes mellitus (T2DM) among rural people is seldom reported in Malaysia. This study aimed to determine the knowledge, attitude, and practice (KAP) of DF intake and their association with type 2 diabetes mellitus (T2DM) among rural people in Terengganu, Malaysia. A community-based cross-sectional study was carried out among the households in Kampung Jati, Kuala Nerus, Terengganu, Malaysia from $29^{\text {th }}$ December 2019 until 20 th February 2020. The village has 524 houses, the data was collected from all available and eligible subjects in each household by completed socio-demographic, validated KAP on DF intake questionnaire, as well as a 24-hour dietary recall using a self-administered questionnaire. In our study of 396 respondents, 208 (52.5\%) were men. The mean age of participants was 37.85 (15.13). Most of the subjects were Malay 384 (97.0\%), employed 207 (52.3\%) and 274 (69.2\%) attained high level of education (from tertiary school level). However, only 170 (42.9\%) had a high family income which was of >RM 3860 per month. Out of 396 respondents, 157 (39.6\%) of them had family history of diabetes mellitus. Respondents had moderate knowledge (39.1\%), positive attitude (88.1\%) and good practice (59.3\%) scores towards DF intake. Among the respondents, only $39.1 \%$ of total respondents knew the nationally recommended amount of daily fibre intake which is of 20-30 grams per day. With multivariable analysis using multiple logistic regression, the analysis results revealed that age (adjusted OR: 1.11, 95\% Cl: 1.08, 1.15; $p<0.001$ ), having family history of T2DM (adjusted OR: 6.81, 95\% CI: 2.75, 16.84; $p<0.001$ ) and having total attitude scores (adjusted OR: 0.84, 95\% $\mathrm{Cl}: 0.76,0.93 ; p<0.001)$ were found to be adjusted significant associated factors of T2DM among the respondents after controlling confounders. Public health authorities should raise awareness on health benefit of consuming dietary fibre to promote an increase in consumption which can help in prevention and management of chronic diseases among rural population of Malaysia.
\end{abstract}

KEYWORDS: Dietary fibre intake, KAP, Family history, Diabetes mellitus, Awareness.

\section{INTRODUCTION}

Type 2 diabetes mellitus (T2DM) is one of the leading global health crises. Out of different types of diabetes, type 2 diabetes mellitus (T2DM) is more common and occurs in $90 \%$ of people with diabetes all over the world. ${ }^{1}$ The number of diabetes cases has been steadily increasing over the past few decades. Globally, it was anticipated that by 2030 the prevalence of T2DM among people of all ages would be double of $2.8 \%$ in the year $2000 .^{2}$ The World Health Organization (WHO) reported a more severe projection for the middle-income countries than the rich nations. ${ }^{3}$ In Malaysia, National Health and Morbidity Survey 2019 reported that an increase in T2DM prevalence from $17.5 \%{ }^{4}$ in 2015 to $18.3 \%$ in 2019. ${ }^{5}$

A clinical audit on 396 medical records of diabetic patients from two urban public primary care clinics revealed mean glycated haemoglobin (HbA1C) of $8.3 \%$, with only $15.6 \%$ of all patients managed to keep the HbA1C level below $6.5 \%{ }^{6}$ All of these powerful studies established that the ideal HbA1C level was achieved by less than one-third of the overall patients with diabetes. Unlike the fasting blood glucose, $\mathrm{HbA} 1 \mathrm{C}$ is a long-term marker of serum sugar level and represents the degree of diabetic control over the past 2-3 months. ${ }^{7}$ An increase in $\mathrm{HbA} 1 \mathrm{C}$ therefore, suggests an elevated risk of developing multiple diabetic-related complications. Hence, research among Malaysian population on T2DM send a strong message; there is a worrying trend of increased prevalence and poor control of T2DM among the public in Malaysia. ${ }^{8}$

The foundation of T2DM management aims at reducing risks via promoting healthy lifestyle. Although medical management typically involves pharmacological interventions with the escalation of treatment is set to match the severity of the disease and its complications, this should remain as the secondary approach. Weight management, healthy diet, and regular aerobic exercises 
constitute the main pillar of therapy, and more resources need to be invested to optimise these conservative approaches.

In response, we are investigating dietary fibre as one of the recognized dietary regiments beneficial to the management of T2DM. The primary sources of dietary fibres are from vegetables, fruits, whole grains, legumes, and all plant-derived food products. Three meta-analysis studies demonstrated significant protective factors of consuming higher cereal fibre against developing T2DM and its complications. 9,10,11 Physiologically, Dhingra et al, $2012^{12}$ explained that fibres could replace the energy from other nutrients, especially carbohydrates, by adding weight and bulk to the meal. As a result, the body received a comparable volume of dietary intake, low in glycaemic index, yet at a low energy density, leading to early satiation without extreme surges and fluctuations in serum glucose and insulin level. ${ }^{13}$ Hence, in the long term, a consistent regiment of adequate dietary fibre may also help in weight management and the associated improved insulin resistance.

Unfortunately, it is not uncommon for the adult population to consume an insufficient amount of dietary fibre. Existing data suggest doubling the average daily dietary fibre is necessary to meet the recommended amount of $22 \mathrm{~g}-38 \mathrm{~g}$ daily. ${ }^{14}$ Based on the practical implications and the current estimated total fibre intake of Malaysians, the expert panel on Malaysian Dietary Guidelines $(2010)^{15}$ has recommended the dietary fiber goal of at least $25 \mathrm{~g}$ per day as consistent with a healthy lifestyle and diet. This recommendation suggested more systematic community-based intervention is warranted.

The prevalence of T2DM in Terengganu itself was $18.6 \%$ in 2015 , and it was ranked $7^{\text {th }}$ out of 14 states in Malaysia. ${ }^{16}$ To the best of our knowledge, there is no study being conducted to assess the knowledge, attitude, and practice of a community in Terengganu on dietary fibre related to diabetes. This study, therefore, addressed this gap to provide evidence and to gain a deeper understanding of this critical public health issue, and was conducted among a community in a residential area near the city of Kuala Terengganu, in a state of Terengganu, Malaysia.

\section{METHODS}

A community-based cross-sectional study was carried out among the households in Kampung Jati, Kuala Nerus, Terengganu, Malaysia from $29^{\text {th }}$ December 2019 until $20^{\text {th }}$ February 2020. The village has 524 houses, and most of the residents are Malay. Inclusion criteria included adults aged 20 years or older and those who were able to read in Malay language. Those who were terminally ill or had mental problem were excluded from this study. The data was collected from all available and eligible subjects in each household by using a selfadministered questionnaire.

The items in the questionnaire were developed and made up mostly from the questionnaire of the study done in 2018 by Daud et al, 2018. ${ }^{17}$ The newly developed questionnaire was composed of 58 questions divided into five domains: sociodemographic, knowledge, attitude, practice, and status of T2DM of the respondents. The knowledge, attitude and practice domains consisted of 24,12 and 14 items, respectively. The contents of the questionnaire were validated by panel of public health specialists for the relevance to the studied community. The questionnaire was originally in English. Then, it was translated into Malay language and back translated into English by bilingual persons based on the standard guidelines. Face validity was evaluated with 10 people about the understanding of the questionnaire. Next, the validation study was conducted among 149 respondents at Kampung Batu Buruk, Kuala Neru. Items with factor loading of 0.30 and above were considered acceptable.

The final validated questionnaire consisted of five parts (A, B, C, D and E) with 40 closed-ended questions all in all. Part $A$ included seven questions regarding socio-demographic details. Part B was constructed with 17 items assessing the knowledge about dietary fibre intake. Every single item in part B had "yes", "no" or "don't know" answer options. The correct answer was scored as two marks, the wrong answer as zero marks and "don't know" answer as one mark. Part $\mathrm{C}$ was about the attitude towards dietary fibre intake, and it was comprised of 6 items. The attitude was evaluated using five levels of Likert scale where were "strongly agree", "agree", "neutral", "disagree", and "strongly disagree" responses. Five scores were given to "strongly agree" response and one score to "strongly disagree" response in each positive statement. Part D entailed 9 questions probing the practice of dietary fibre intake with "yes" or "no" options. One mark was given to the "yes" answer whereas zero mark to "no" answer in a positive statement. The reserve score ratings were applied for each negative statement in the part $D$. The last part $E$ had one question identifying whether the respondent had confirmed type 2 diabetes mellitus (T2DM) which was diagnosed by any health care provider. The required sample size for this study was computed using two-proportions formula by applying the power and sample size calculation software. ${ }^{18}$ Considering $80 \%$ test power, the minimum total required sample size was 338 respondents for this study. 


\section{Ethical approval:}

The written informed consent was taken from all participants before the administration of the survey questionnaire. The respondents were given assurance on the confidentiality of all the information given. The information about all respondents' data was kept private and confidential, without requiring them to reveal their identities. The ethics approval to conduct this study was obtained from UniSZA Human Research Ethics Committee (UHREC) on $16^{\text {th }}$ January 2020 (Reference no: UniSZA.C/2/UHREC/628-2 Jld 2(22)).

\section{Statistical analysis}

Data analysis was conducted using statistical package for the social sciences (SPSS) version 22. ${ }^{19}$ Data exploration and cleaning was carried out. Then, descriptive statistics was applied such as frequency (percentage) for categorical data and mean (standard deviation) for numerical data. The proportion of T2DM cases was presented with percentage and its $95 \%$ confidence interval. To identify the potential candidate significant variables, simple logistic regression was performed. Selection of variables for multivariate analyses was based on three factors - the statistical significance in univariable analysis ( $P$-value of $<0.250)$, the principles of parsimony and biological plausibility. After that, multiple logistic regression with forward likelihood ratio (LR) method was carried out to identify the associated factors of having T2DM with regards to their socio-demographic variables, knowledge, attitude, and practice of dietary fibre intake. Multicollinearity and interactions were checked. The fit of the final statistical model was then checked by Hosmer-Lemenshow goodness-offit test, overall, correctly classified percentage from classification table and the area under receiver operating characteristic (ROC) curve. The results were presented by using crude and adjusted odds ratio (OR) with $95 \%$ confidence interval $(\mathrm{Cl})$, Wald statistic, regression coefficient $(b)$ and corresponding $P$-value. The level of significant was set at 0.05 .

\section{RESULTS}

Socio-demographic characteristics of respondents The characteristics of the study participants were summarized in (Table. 1). A total of 396 respondents, including 208 men $(52.5 \%)$ and 188 women $(47.5 \%)$ participated in this survey. The mean age (SD) of participants was 37.85 (15.13). Most of the subjects were Malay $384(97.0 \%)$, employed 207 (52.3\%) and 274 (69.2\%) attained high level of education (from tertiary school level). However, only 170 (42.9\%) had a high family income which was of >RM 3860 per month. Out of 396 respondents, $157(39.6 \%)$ of them had family history of diabetes mellitus.

Table 1: Socio-demographic characteristics of adult respondents $(n=396)$

\begin{tabular}{llc}
\hline Variables & & Frequency (\%) \\
\hline Gender & Male & $208(52.5)$ \\
Age & Female & $188(47.5)$ \\
Ethnicity & Mean (SD), years & $37.85(15.13)$ \\
& Malay & $384(97.0)$ \\
Occupation & Non-Malay & $12(3.0)$ \\
& Employed & $207(52.3)$ \\
Educational status & Unemployed including students & $189(47.7)$ \\
& High level of education & $274(69.2)$ \\
Family income & Low level of education & $122(30.8)$ \\
& Low family income & $226(57.1)$ \\
Family history of diabetes & High family income & $170(42.9)$ \\
& Present & $239(60.4)$ \\
\hline
\end{tabular}


Exploratory factor analysis and internal consistency

Table $2 \mathrm{a}$ and $2 \mathrm{~b}$ present the construct validity and reliability analyses of questionnaire on knowledge, attitude, and practice about the dietary fibre intake among respondents. Reliability analysis of the questionnaire showed that Cronbach's alpha values for all knowledge, attitude and practice parts were good and had $0.86,0.77$ and 0.86 , respectively. The overall Cronbach's alpha for these three domains was 0.83 . The questionnaire is valid and reliable

Table 2a: Construct validity and reliability analyses of questionnaire on knowledge, attitude about the dietary fibre intake among respondents $(n=149)$

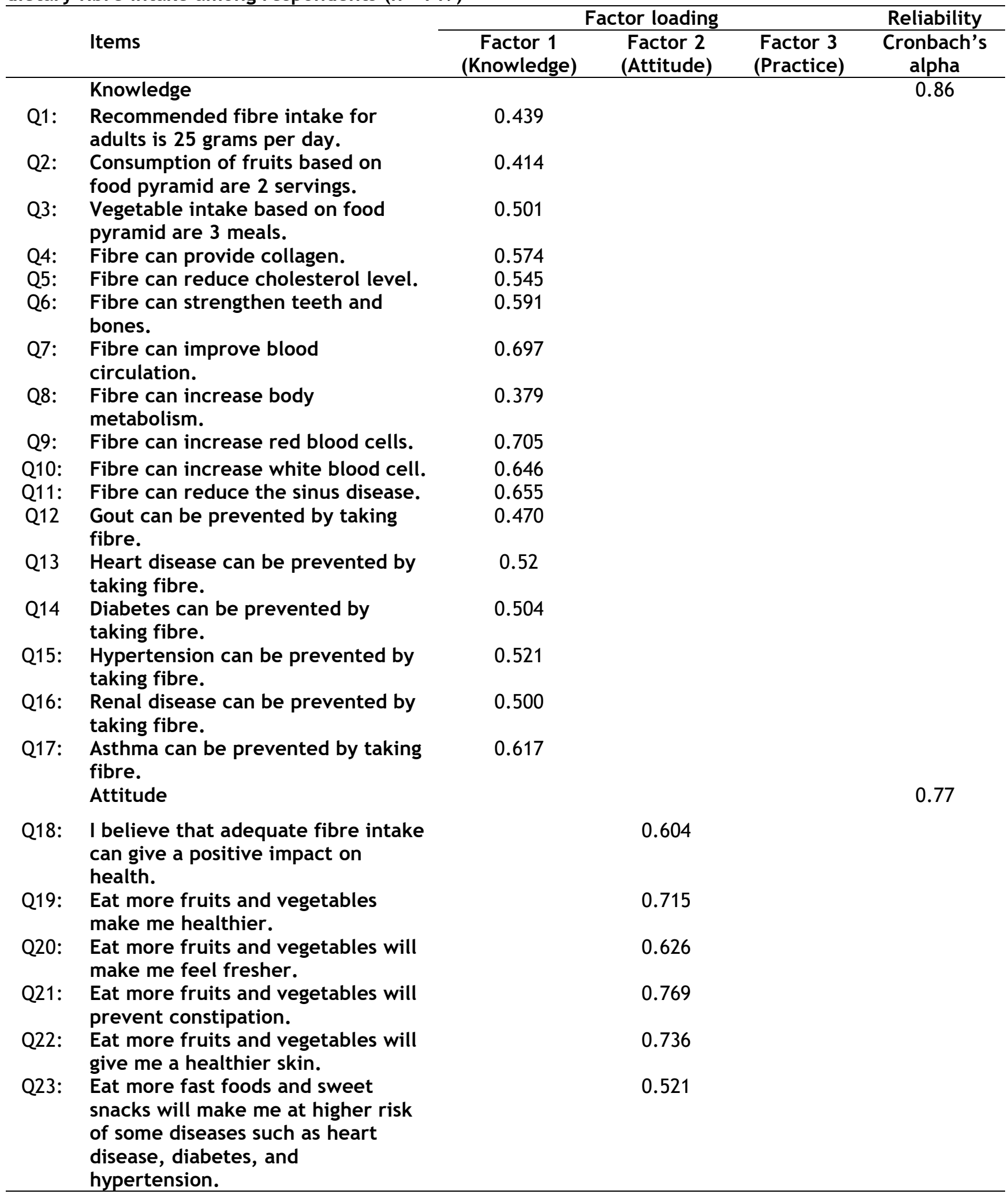


Table 2b: Construct validity and reliability analyses of questionnaire on practice about the dietary fibre intake among respondents $(n=149)$

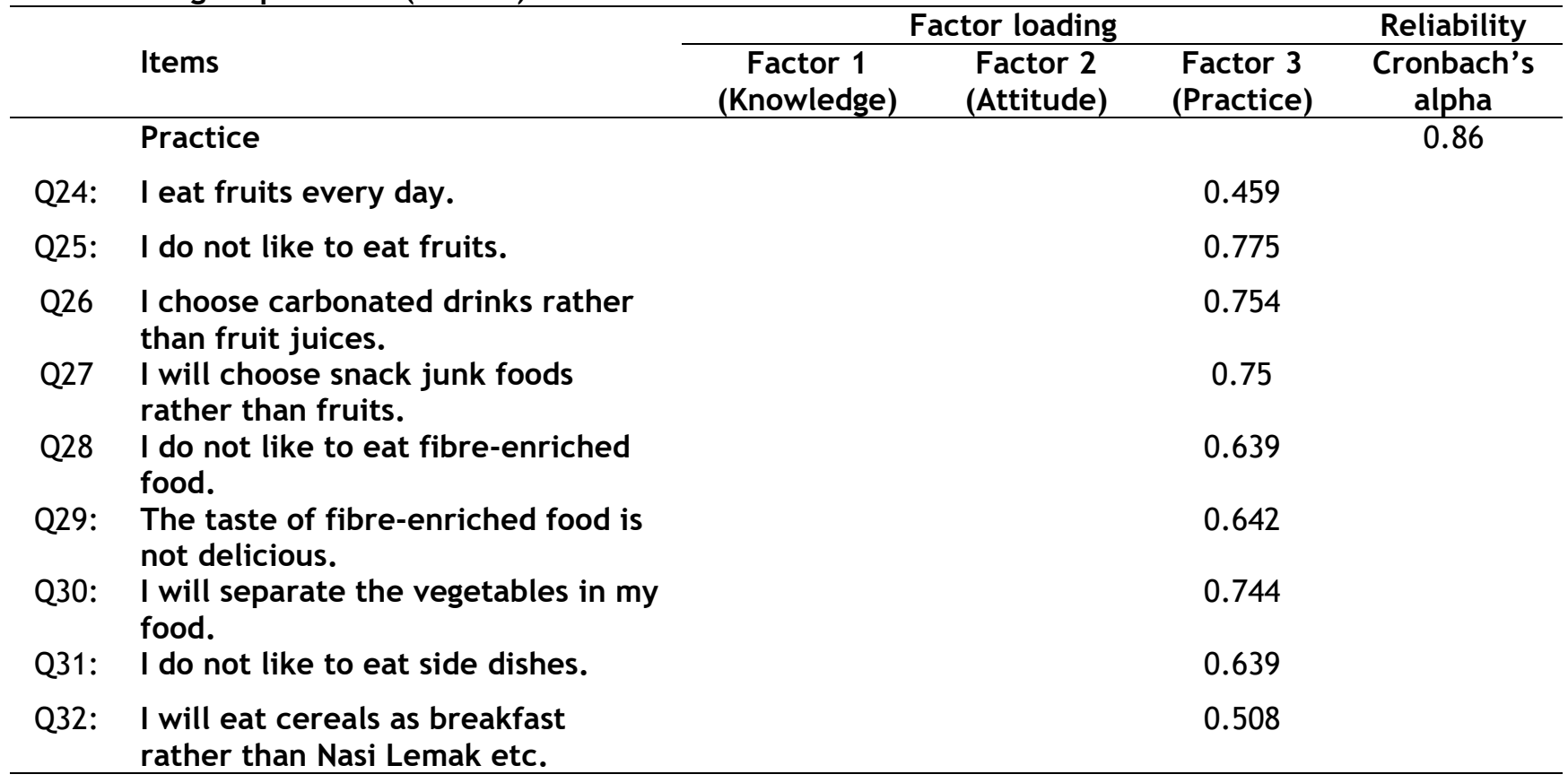

Knowledge about the dietary fibre intake among respondents

Among the respondents, only $39.1 \%$ of total respondents knew the nationally recommended amount of daily fibre intake which is of 25 grams per day. However, more than half of the subjects knew that fruits need to be consumed in 2 servings (57.1\%), and vegetables need to be taken up in 3 serving daily (57.8\%) based on the food pyramid. Focusing on the benefits of fibre intake, majority recognized that fibres could provide collagen $(51.0 \%)$, help in reducing cholesterol level $(66.9 \%)$, strengthen teeth and bones (48.5\%), improve blood circulation (56.3\%), increase body metabolism $(66.7 \%)$ and red blood cells $(49.0 \%)$. Yet, slightly more than half of them were uncertain that fibres can increase white blood cells $(53.3 \%)$ and reduce the sinus diseases (52.0\%). Regarding the knowledge on dietary fibre to facilitate primary prevention of chronic diseases, most respondents were aware that fibre intake could prevent gout $(48.2 \%)$, heart diseases $(60.9 \%)$, diabetes $(66.4 \%)$, hypertension (56.3\%) and renal diseases (54.3\%). On the other hand, about half of the respondents $(58.1 \%)$ were unsure that asthma is preventable by taking dietary fibre.

Attitude towards dietary fibre intake among respondents

In the matter of attitude towards daily fibre intake, about $88.1 \%$ of the subjects acknowledged that adequate fibre intake could give a positive impact on health. Majority of the respondents agreed that eating fruits and vegetables is essential for health
(95.2\%) and the feeling of refreshment (91.7\%). Furthermore, most of the participants also accepted that consumption of more fruits and vegetables would prevent constipation (82.3\%) and give them a healthier skin (94.2\%). Concerning fast foods and sweet snacks, most respondents $(86.4 \%)$ already had an opinion that eating fast foods will make them at higher risk of some diseases such as heart disease, diabetes, and hypertension.

Practice of dietary fibre intake among respondents

More than half of the respondents (59.3\%) consumed fruits every day, and only some people $(19.7 \%)$ did not like to eat fruits. Most participants did not favour junk food rather than fruits $(75.5 \%)$, and they would choose fruit juices rather than carbonated drinks (76.5\%). Regarding the fibre-enriched food, most people love to consume it $(70.5 \%)$ and agreed fibre-enriched foods are delicious (69.9\%). Thus, they would not separate the vegetables from their food $(71.0 \%)$. More than half of the respondents preferred to eat side dishes (58.3\%) and cereals for breakfast rather than nasi lemak and others (51.5\%).

Total knowledge, attitude and practice scores of dietary fibre intake among respondents

In accordance with the scoring system stated in the methodology, the respondents' total knowledge scores ranged from 5 to 34 with mean value (SD) of 24.17 (5.87). As for the total attitude score, it fluctuated from 6 to 30 with mean score (SD) of 
26.09 (3.86). The total practice scores were from 2 to 9 with mean score (SD) of $5.96(1.83)$.

\begin{abstract}
Associated factors of T2DM among adult respondents.

Based on the univariable analysis results by means of simple logistic regression, the respondents' socio-demographic characteristics such as age (crude OR: 1.11, 95\% Cl: 1.08, 1.14; $\mathrm{p}<0.001$ ), occupation (crude OR: $2.10,95 \% \mathrm{Cl}: 1.06,4.18 ; \mathrm{p}=$ 0.034 ), educational status (crude OR: $4.23,95 \% \mathrm{Cl}$ : 2.13, 8.39; $p<0.001$ ), having high family income (crude OR: $0.49,95 \% \mathrm{Cl}: 0.24,1.01 ; \mathrm{p}=0.054$ ), having family history of T2DM (crude OR: $5.19,95 \%$ $\mathrm{Cl}: 2.45,10.99 ; \mathrm{p}<0.001)$ and having total attitude scores (crude OR: 0.83, 95\% Cl: 0.77, 0.90; $p$ < 0.001 ) were found to be significant, unadjusted associated factors of having T2DM among the respondents when no other confounding variables were considered.
\end{abstract}

With multivariable analysis using multiple logistic regression, the analysis results revealed that age ( $p$ $<0.001)$, having family history of T2DM ( $p<0.001)$ and having total attitude scores $(p<0.001)$ were found to be adjusted significant associated factors of T2DM among the respondents after controlling confounders (Table 3 ).

The model reasonably fitted well. The fit of the statistical model was checked by HosmerLemenshaw test $(p=0.924)$, overall, correctly classified percentage (92.2\%) and the area under ROC curve (93.6\%; 95\% Cl: 90.6, 96.5, $\mathrm{p}<0.001)$. The final model showed that an increase in one year of age had 11\% more likely to have T2DM (adjusted OR $=1.11,95 \% \mathrm{Cl}: 1.08,1.15)$, those with family history of T2DM had 6.81 time more likely to have T2DM (adjusted OR $=6.81,95 \% \mathrm{Cl}: 2.75,16.84$ ) whereas an increase in one score of total attitude scores had $16 \%$ less likely to have T2DM (adjusted OR $=0.84$, $95 \% \mathrm{Cl}: 0.76,0.93)$.

Table 3: Associated factors of T2DM among adult respondents $(n=396)$

\begin{tabular}{|c|c|c|c|c|c|c|c|c|}
\hline \multirow[b]{2}{*}{ Variables } & \multicolumn{4}{|c|}{ Simple Logistic Regression } & \multicolumn{3}{|c|}{ Multiple Logistic Regression } & \multirow[b]{2}{*}{$\begin{array}{c}P \\
\text { Value }\end{array}$} \\
\hline & b & $\begin{array}{c}\text { Crude OR } \\
(95 \% \mathrm{Cl})\end{array}$ & $\begin{array}{l}\text { Wald } \\
\text { Stat }\end{array}$ & $\begin{array}{c}P \\
\text { Value }\end{array}$ & $b$ & $\begin{array}{l}\text { Adjusted OR } \\
(95 \% \mathrm{Cl})\end{array}$ & $\begin{array}{l}\text { Wald } \\
\text { Stat }\end{array}$ & \\
\hline Age in years ${ }^{a}$ & 0.10 & $1.11(1.08,1.14)$ & 44.40 & $<0.001$ & 0.11 & $1.11(1.08,1.15)$ & 38.40 & $<0.001$ \\
\hline $\begin{array}{l}\text { Family } \\
\text { history of } \\
\text { T2DM }\end{array}$ & & & & & & & & \\
\hline $\begin{array}{l}\text { Absent } \\
\text { Present }\end{array}$ & $\begin{array}{c}0 \\
1.65\end{array}$ & $\begin{array}{c}1.00 \\
5.19(2.45,10.99)\end{array}$ & 18.48 & $<0.001$ & $\begin{array}{c}0 \\
1.92\end{array}$ & $\begin{array}{c}1.00 \\
6.81(2.75,16.84)\end{array}$ & 17.21 & $<0.001$ \\
\hline $\begin{array}{l}\text { Attitude } \\
\text { scores }^{a}\end{array}$ & -0.18 & $0.83(0.77,0.90)$ & 21.91 & $<0.001$ & -0.18 & $0.84(0.76,0.93)$ & 12.20 & $<0.001$ \\
\hline
\end{tabular}

aMean (SD); ${ }^{b}$ Forward likelihood ratio Multiple Logistic regression; There were no interaction and multicollinearity problems detected.

The model reasonably fits well. The fit of the model was checked by Hosmer-Lemenshaw test $(p=$ 0.924), overall, correctly classified percentage $(92.2 \%)$ and the area under ROC curve $(93.6 \%$; $95 \%$ $\mathrm{Cl}$ : 90.6, 96.5; $\mathrm{p}<0.001)$.

\section{DISCUSSION}

To our knowledge, this is the first study to investigate the prevalence of Type2 Diabetes Mellitus (T2DM), knowledge, attitude, and practice (KAP) on dietary fibre and association between dietary fibre KAP with T2DM within a Malay population in the East Coast state of the peninsular Malaysia. The studied community were residing $15 \mathrm{~km}$ from the city of Kuala Terengganu, semiurban, with education and tourism are the main drivers of the economy. Thus, due to its unique context, findings of this study offered a new perspective on the topic.

The new understanding is evident on the T2DM prevalence among this community at $9.8 \%$, which is lower than the national average of $18.3 \%$ in 2019. The difference is potentially attributable to the distinct age profile of participants. Table 1 showed the mean age by years of this population at 37.85 , considerably younger than the national average. In comparison, Letchuman et al. $(2010)^{4}$ was conducting a cross-sectional study for the Malaysian National Health Morbidity Survey III (NHMS III), which included face-to-face interviews of 34,539 participants aged of 18 or older. This nation-wide influential study found a generally increasing trend in type 2 diabetes mellitus prevalence with age, from $2.0 \%$ in the $18-19$ years old age group to a prevalence ranging between 20.8 to $26.2 \%$ among 
the 60-64 age group. This insightful evidence was also consistent with our findings that age is significantly associated with the T2DM (Table 3). Therefore, although the national data serves as a powerful benchmark on T2DM prevalence, our study demonstrates that understanding T2DM prevalence for a specific community in Malaysia may differ, and likely contextual by considering the mean age of the studied population.

This finding, however, is not surprising because T2DM is a chronic disease that has a strong association with lifestyle. Significant T2DM association with age suggests that the community of our study may have been undertaking lifestyle and health behaviour which predisposed their risk of developing T2DM with time. A review of the literature by Hussein et al. $(2015)^{20}$ provided invaluable insight into this finding. They searched, screened, and selected from pre-defined inclusion criteria the literature on diabetes from health care data, publications, and clinical observations. The review found that an increase in obesity accompanies the increase in T2DM prevalence. ${ }^{20}$ Although our study did not directly investigate the prevalence of obesity in this community, the association between obesity and urban life has been well-established. Aspects of urban life such as highcalorie diet, less open space, less physical-related with more roads and cars, and less walking and cycling, may have contributed to the risk of developing T2DM over time. ${ }^{21}$ Thus, the results demonstrated the critical aspect of primary prevention at the younger age group as the pillar of T2DM management.

Consequently, employment which was negatively associated with the T2DM emerged as one of the key strategies to achieve this goal. Unemployment has been recognized as an economic issue with significant health repercussion. ${ }^{22}$ Being employed brings sense of identity, purpose, access to community, experience and opportunity to grow in personal and professional capacity. ${ }^{23}$ The consequent benefits on mental health influence quality of life with direct consequences to the lifestyle-related chronic health diseases. A powerful cross-sectional study by Borhanuddin et al, $2018^{24}$ researched among 105,391 Malaysian adults in 20 job sectors consolidated this assertion. The nationwide study found T2DM prevalence was highest accommodation and food service activities with unemployed/ homemaker emerged as the single job sector with the highest prevalence of hypercholesterolaemia. ${ }^{24}$ Employment illuminates the biopsychosocial framework of health determinants which explain the prevalent of T2DM in this community. Therefore, our findings suggest the holistic prevention strategies against T2DM need to depart from approach that transgress beyond just health and education, but also the economy.

Nevertheless, dietary fiber, which is recognized as protective against developing T2DM, remains integral for the T2DM primary prevention. Almost all respondents agree on the health benefits of dietary fibre and the need to reduce the consumption of fast food, sweet drink, and savoury snacks. An interesting study by Lee \& Muda (2019) ${ }^{25}$ provided evidence to support this statement. They interviewed 422 Malaysian adults on their dietary intake for the last three days and measured their weight, height, and waist circumference. The analyses revealed the majority of respondents who were obese reported having lower consumption of fruits and vegetables. ${ }^{25}$ The empirical result by Lee \& Muda (2019) ${ }^{25}$ is further substantiated by an extensive umbrella review of the literature by McRae (2018). ${ }^{9}$ The review of the systematic review investigated 16 meta-analyses for the literatures from 1 January 1980 to 30 April 2017, specifically looking at reviews and empirical studies on the evidence of dietary fibre on T2DM. By comparing the highest and the lowest intake of the dietary fibre, the umbrella review demonstrated that there was a statistically significant reduction in the relative risk (RR) of type 2 diabetes $(R R=0.81$ 0.85 ), with the most significant benefit coming from cereal fibres ( $R R=0.67-0.87) .{ }^{9}$ It is important to note that the study did not set boundaries for geographical locations or ethnicity of participants. Thus, the protective benefits of cereal fibre against T2DM are likely universal and applicable to the Malaysian setting as well.

Interestingly, despite the earlier findings that associate T2DM with age, the high level of education may explain good knowledge among participants on the benefits of dietary. About half to three-quarters of all respondents were aware of the range of health benefits offered by the dietary fibre. This knowledge may be explained by most respondents who attained a high level of education. In 2013, the Malaysian government published the Malaysian Education Blueprint in response to the emerging trend of the curriculum towards competency-based education (CBE). ${ }^{26}$ Unlike the traditional time-based and content-based curriculum, CBE advocates outcomes as the primary design of the curriculum to ensure holistic graduates who can meet and exceed the needs and expectations of the society. ${ }^{27}$ Hence, a high level of education among most of our respondents with a corresponding good awareness of dietary fibre is paramount.

This importance is further supported by the significant association between educational status with T2DM in this study (crude OR: $4.23,95 \% \mathrm{Cl}$ : 
$2.13,8.39 ; p<0.001)$. Findings on health education and positive health outcomes have been consistently reported in the literature. A comprehensive systematic review by Rose et al, $2017^{28}$ aggregated 15 studies on the use of digital health as the primary mean of educating adolescent to engage with physical activities and healthy diet. The meta-analyses reported significant behaviour changes were associated with interventions that incorporate education, goal setting, selfmonitoring, and parental involvement. Likewise, Stogios et al, $2020^{29}$ searched, selected and appraised 17 empirical studies on the use of technology-enhanced health education to improve blood pressure. The seminal systematic review reported health education resulted in $7.3 \mathrm{mmHg}$ reduction in systolic blood pressure (95\% confidence interval reduction: 7.0 to 7.5 ) compared with 3.6 $\mathrm{mmHg}$ reduction in the control group $(95 \%$ confidence interval reduction: 3.4 to 3.9), $\mathrm{P}<0.001$, with high-moderate heterogeneity $(\mathrm{I}(2)=67 \%) .{ }^{29}$ With more than 30 empirical studies, both metaanalyses exert strong evidence to substantiate the positive impact on health through education. Therefore, education which lead to awareness and favourable behaviour are the key strategy for healthy dietary intake and T2DM prevention.

The practice of healthy dietary fibre, therefore, is as important, if not more important, than the knowledge and attitude. Our study shows more than $80 \%$ of the respondents reported preference to eat salads, fruits, and vegetables. The amount of consumption, however, appear varied. Despite their favourable dietary preference, almost $40 \%$ did not practice daily fruit intake. At the same time, an almost equal portion would choose high-fat content breakfast (i.e., nasi lemak) over fibre-rich cereal breakfast. Nevertheless, more than $80 \%$ would consume vegetables in every serving, indicating a mixed practice despite a generally favourable attitude towards a fibre-rich diet. The mixed practice, despite good education and awareness indicate multi-faceted aspects with competing factors that influence the final health behaviour among participants.

Social pressure, culture influence, and financial access to healthy diet may contribute to the gaps between attitude and practice. Guldbrand et al, $2014^{30}$ randomized two groups of T2DM into two groups of a low-carbohydrate diet and a low-fat diet. Although the study was primarily focusing on the comparison between the two diets, their follow up at 12 months and 24 months interestingly revealed difficulties among participants to sustain the dietary regiment due to socio-environmental factor due to lack of access to low-carbohydrate diet among local restaurants. ${ }^{30}$ Similar environmental pressure may also contribute to the gaps between favourable knowledge and attitude against the mixed practice of dietary fibre. For example, nasi lemak (coconut rice) is extremely popular among locals with numerous restaurants and street stalls selling and serving it as a breakfast menu, whereas the selling and serving on in-house breakfast cereals are relatively uncommon. Furthermore, high demands also contribute to the lower price of traditional carbohydrate-based menu and meals. For example, a serving of nasi lemak would cost as low as RM2. In contrast, the relatively pricier cereal and high-fibre dietary breakfast mean a smaller number of members of the community would opt for this option. Yet, not all sources of dietary fibre are expensive. Local fruits and vegetables, especially with low glycaemic index such as guava, apples and papaya are readily accessible, explaining the mixed findings of practice in this study. Therefore, improving financial access, either by increasing income or reducing the price, may boost the consumption of dietary fibre.

\section{CONCLUSION}

In summary, our study provides further enlightenment on the prevalence of T2DM and the knowledge, attitude, and practice on dietary fibre among a residential locality in Kuala Terengganu. The findings of this study suggested that being old age, having family history of diabetes were more likely to have T2DM whereas having the good attitude towards dietary fiber intake was less likely to have T2DM. To get the good attitude among the community, the challenges, therefore, lies not only in promoting awareness via campaigns and health promotions. Instead, the primary intervention should have been on capitalizing the existing knowledge and awareness to engineer social changes to improve the current culture and practice towards the recommended healthy dietary intake and lifestyle as the primary prevention against T2DM.

\section{ACKNOWLEDGEMENT}

The authors would like to extend our great appreciation to all Year 3 MBBS students (20192020) and all research participants.

\section{CONFLICT OF INTEREST}

The authors declare no conflict of interest.

\section{REFERENCES}

1. World Health Organization (WHO).
Diabetes. http://www. who.int/dietphysicalactivity/ (accessed 23 May 2020). 
2. Wild S, Roglic G, Green A, et al. Global Prevalence of Diabetes Estimates for the year 2000 and projections for 2030. Diabetes Care 2004. https://pubmed.ncbi.nlm.nih.gov/1511151 9/. (accessed 18 July 2020).

3. World Health Organization (WHO). Diabetes (Key facts), World Health Organization. $2020 . \quad$ https://www.who.int/news$\mathrm{room} /$ fact-sheets/detail/diabetes (accessed 23 May 2020).

4. Letchuman GR, Nazaimoon WMW, Mohamad WBW, et al. prevalence of diabetes in the Malaysian National Health Morbidity Survey III 2006. Med J Malaysia 2010; 65(3):180-6.

5. Ministry of Health Malaysia. National Health and Morbidity Survey 2019: Technical Report- Volume 1: Non-Communicable Diseases: Risk Factors and other Health Problems. 2020. http://iku.moh.gov.my/images/IKU/Docu ment/REPORT/NHMS2019/Report_NHMS20 19-NCD_v2.pdf (accessed 19 December 2020).

6. Sazlina SG, Zailinawati AH, Zaiton A, Ong I. A clinical audit on diabetes care in two urban public primary care clinics in Malaysia. Malaysian Journal of Medicine and Health Sciences 2010;6(1):101-9.

7. Sherwani S, Khan H, Ekhzaimy A, Masood A, Sakharkar M. Significance of HbA1c Test in Diagnosis and Prognosis of Diabetic Patients. Biomark Insights 2016;11:95-104.

8. Chew BH, Mastura I, Lee PY, Wahyu TS, Cheong AT, Zaiton A. Ethnic Differences in Glycaemic Control and Complications: The Adult Diabetes Control and Management (ADCM), Malaysia. Med J Malaysia 2011; 66(3): 244-8.

9. MCRae, MP. Dietary Fiber Intake and Type 2 Diabetes Mellitus: An Umbrella Review of Meta-analyses. J Chiropr Med 2018; 17(1):44-53.

10. Kuijsten A, Aune, D, Schulze $M$, et al. Dietary fibre and incidence of type 2 diabetes in eight European countries: the EPIC-InterAct Study and a meta-analysis of prospective studies. Diabetologia 2015;58(7):1394-408.
11. Schulze, MB, Schulz M, Heidemann C, et al. Fiber and magnesium intake and incidence of type 2 diabetes: A prospective study and meta-analysis. Arch Intern Med 2007; 167(9):956-65.

12. Dhingra D, Michael M, Rajput H, Patil RT. Dietary fibre in foods: A review. J Food Sci Technol 2012;49(3); 255-266.

13. Papathanasopoulos A, Camilleri M. Dietary Fiber Supplements: Effects in Obesity and Metabolic Syndrome and Relationship to Gastrointestinal Functions. Gastroenterology 2010; 1381(1):65-72, e12.

14. World Health Organization (WHO). Healthy diet. 2020. https://www.who.int/news$\mathrm{room} /$ fact-sheets/detail/healthy-diet (accessed 12 August 2021).

15. Ministry of Health Malaysia $(\mathrm{MOH})$. Malaysian Dietary Guidelines. 2010. https: / / nutrition.moh.gov.my/wpcontent/uploads/penerbitan/buku/Malaysi a Dietary Guidelines 2010.pdf (accessed 12 August 2021).

16. Ministry of Health Malaysia $(\mathrm{MOH})$. Diabetes care performance report. 2016. https://www. researchgate.net/publication /277833167_A_Clinical_Audit_on_Diabetes _Care_in_Two_Urban_Public_Primary_Care _Clinics_in_Malaysia/link/55b772aa08aec0 e5f4381d2b/download (accessed 24 July 2020).

17. Daud NM, Fadzil NI, Yan LK, Makbul IAA, Yahya NFS, Teh $\mathrm{AH}$, et al. Knowledge, attitude and practice regarding dietary fibre intake among Malaysian rural and urban adolescents. Malays $J$ Nutr 2018;24(1):77-88.

18. Dupont W, Plummer W. Power and Sample Size Calculations: A Review and Computer Program. Control Clin Trials 1990;11:11628.

19. IBM Corp. IBM SPSS Statistics for WindowS. Armonk, NY: IBM Corp. 2013.

20. Hussein Z, Taher SW, Gilcharan Singh HK, Chee Siew Swee W. Diabetes Care in Malaysia: Problems, New Models, and Solutions. Ann Glob Heal 2015;81(6):85162.

21. Harvard School of Public Health. Obesity Prevention 2020. 
https: / /www.hsph.harvard.edu/obesityprevention-source/obesity-and-

urbanization/ (accessed 22 August 2021).

22. Michalski W, Miller R, Stevens B. Towards the creative society: 21 st century social dynamics. Foresight 2000;2(1):85-94.

23. Ramawickrama J, Ratnayaka RM. The impact of employee benefits on job satisfaction. $2008 . \quad$ http://irep.emu.edu.tr:8080/xmlui/handle/11129 /1658 (accessed 22 August 2021).

24. Borhanuddin B, Ahmad N, Shah SA, Murad NAA, Zakaria SZS, Kamaruddin MA, et al. Association of job sectors with type 2 diabetes mellitus, hypercholesterolemia and obesity: a cross-sectional study from the Malaysian Cohort (TMC) project. Int Health 2018;10(5):382.

25. Lee YY, Muda WAMW. Dietary intakes and obesity of malaysian adults. Nutr Res Pract 2019;13(2):159-68.

26. Ministry of Education Malaysia. Malaysia Education Blueprint 2015-2025 (Higher Education). 2015

https: / /www.um.edu.my/docs/ummagazine/4-executive-summary-pppm2015-2025.pdf (accessed 22 August 2021).

27. Carraccio C, Englander R, Melle E, Cate O, Lockyer J, Chan $M$, et al. Advancing Competency-Based Medical Education: A Charter for Clinician-Educators. Acad Med 2016;91(5):645-9.

28. Rose $\mathrm{T}$, Barker M, Jacob C, Morrison L, Lawrence W, Strömmer S, et al. A systematic review of digital interventions for improving the dietand physical activity behaviours of adolescents. J Adolesc Health 2017; 61(6):669.

29. Stogios N, Kaur B, Huszti E, Vasanthan J, Nolan R. Advancing Digital Health Interventions as a Clinically Applied Science for Blood Pressure Reduction: A Systematic Review and Meta-analysis. Can J Cardiol 2020;36(5):764-74.

30. Guldbrand H, Lindström T, Dizdar B, Bunjaku B, Östgren C, Nystrom F, et al. Randomization to a low-carbohydrate diet advice improves health related quality of life compared with a low-fat diet at similar weight-loss in Type 2 diabetes mellitus. Diabetes Res Clin Pract 2014;106(2):221-7. 